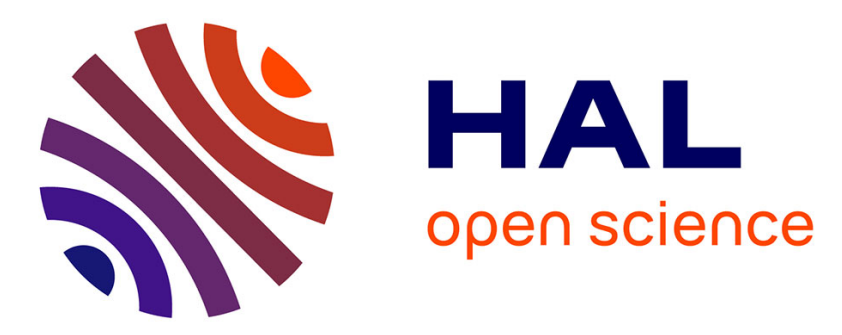

\title{
The future of urban models in the Big Data and AI era: a bibliometric analysis (2000-2019)
}

Marion Maisonobe

\section{To cite this version:}

Marion Maisonobe. The future of urban models in the Big Data and AI era: a bibliometric analysis (2000-2019). AI \& Society: Knowledge, Culture and Communication, 2022, 37 (1), pp.117-194. 10.1007/s00146-021-01166-4 . hal-02386954v5

\section{HAL Id: hal-02386954 https://hal.science/hal-02386954v5}

Submitted on 23 Mar 2021

HAL is a multi-disciplinary open access archive for the deposit and dissemination of scientific research documents, whether they are published or not. The documents may come from teaching and research institutions in France or abroad, or from public or private research centers.
L'archive ouverte pluridisciplinaire HAL, est destinée au dépôt et à la diffusion de documents scientifiques de niveau recherche, publiés ou non, émanant des établissements d'enseignement et de recherche français ou étrangers, des laboratoires publics ou privés. 


\title{
The future of urban models in the Big Data and AI era: a bibliometric analysis (2000-2019).
}

\author{
Marion Maisonobe ${ }^{1}$ \\ 1 marion.maisonobe@cnrs.fr \\ CNRS, Géographie-cités UMR 8504 CNRS, Paris (France)
}

\begin{abstract}
This article questions the effects on urban research dynamics of the Big Data and AI turn in urban management. Increasing access to large datasets collected in real time could make certain mathematical models developed in research fields related to the management of urban systems obsolete. These ongoing evolutions are the subject of numerous works whose main angle of reflection is the future of cities rather than the transformations at work in the academic field. Our article proposes grasp the scientific dynamics in areas of research related to two urban systems: transportation and water. The article demonstrates the importance of grasping these dynamics if we want to be able to apprehend what the urban management of tomorrow's cities will be like. To analyse these research areas' dynamics, we use two complementary materials: bibliometric data and interviews. The interviews conducted in 2018 with academics and higher education officials in Paris and Edinburgh suggest avenues for hybridization between traditional modelling approaches and research in machine learning, artificial intelligence and big data. The bibliometric analysis highlight the trends at work: it shows that traffic flow as well as transportation studies are focussing more and more on AI and Big Data and that traffic flow studies are arousing a growing interest among computer scientists, while, so far, this interest is less pronounced in the water research area, and more especially regarding water quality. The differences observed between research on transportation and that on water confirm the multifaceted nature of the developments at work and encourage us to reject overly hasty and simplistic generalisations about the transformations underway.
\end{abstract}

Keywords: bibliometrics, urban modelling, research dynamics, science studies

\section{Introduction}

Models serves in urban management for both predicting and simulating the dynamics of urban systems. However, the "data deluge" has prompted some commentators, and in particular Chris Anderson, Editor-in-chief of Wired magazine, to question the future of models and theory (Anderson 2008). With advances in AI and city analytics, a growing number of scholars especially question the future of urban models (Kandt and Batty 2021). As discussed in the collective book "Data and the City" (Kitchin et al. 2017), urban dashboards and real-time monitoring relying on a growing amount of sensors are transforming the way urban system are managed.

Although more and more researchers working with urban data evoke the changes at work, they do so mainly to define the contours of new research fields such as Urban Science (Lobo et al. 2020), Urban Computing (Zheng et al. 2014), Urban Big Data (Pan et al. 2016), or Computational Socioeconomics (Gao et al. 2019). These programmatic proposals testify to the fact that we are in a period of recomposition of urban research, a renewed will to integrate approaches from statistical physics and computer science and a growing need to know how to deal with a very large amount of data. However, these proposals do not directly analyse the effect of these transformations on the management of specific urban systems, nor do they study the institutional transformations taking place in the academic world and the scenarios of possible evolution as we propose to do here.

Urban models traditionally developed for urban management purposes are based on data and communities of researchers that are sometimes very distant and the implementation of these models is based on connections with private players and public services that are also compartmentalised (Engin et al. 2020; Kitchin et al. 2017). It is, therefore, quite possible that the research dynamics at work concerning a particular urban system and a particular urban issue are distinct from those dealing with another urban system and another urban issue. To grasp these possible differences and apprehend the changes at work, we use a 
mixed methodology combining a series of interviews with researchers of different disciplines (operational research, applied mathematics, hydrology, computer science, urban modelling) involved in different urban system (climate, transport, water, buildings) and a bibliometric analysis. Drawing upon the content of the interviews, we decide to focus the bibliometric analysis on two urban systems that seemed to be undergoing distinct evolutions, and which mobilise very distinct data and knowledge: transportation and water; and within these fields, we complement our analysis in focussing on two specific urban issues: traffic flow and water quality. To identify current research dynamics, we consider two main questions:

(1) Do scholars in academic fields and sub-fields traditionally related to urban management tend to improve their classic models by taking into account the growing amount of real-time data available on urban systems?

(2) Do academics specialized in data handling tend to be more and more interested in the opportunity of applying AI and Big Data technologies to the management of urban systems?

The article is organised into four sections. The first section of the article presents the state-of-the-art. The second section details the data and methodology as well as the possible scenarios of evolution. The third section displays the results of the bibliometric analysis (1) on transport and water and (2) on traffic flow and water quality issues, and the fourth section discusses the fact that ongoing transformations do not necessarily imply an obsolescence of expert knowledge on urban systems and urban modelling methods.

\section{The Big Data and AI era}

\subsection{The Big Data and AI era in urban management}

There is a growing literature on the adoption of smart urban dashboards, on the installation of sensors and on the use of citizens' devices and cards to collect real-time data and, consequently, on the ongoing changes in the way municipalities are managing their urban systems (Bassoo et al. 2018; Gray et al. 2016; Jesse 2018; Crandall 2010). These changes are raising issues regarding the quality, volume and provenance of data (Engin $e t$ al. 2020; Kitchin et al. 2017). The role of the citizens, their ability to take advantage and be part on the ongoing changes are also under study in the smart city literature (Komninos 2016). Empirical research on the case of Glasgow testifies citizens have not been as much involved as it was expected so far (Borkowska and Osborne 2018). To overcome the narrow vision of citizens as sensors (Goodchild 2007), Borkowska and Osborne argue for making smart cities more inclusive. The social dimension of smart cities is also the focus of Anttiroiko et al. (2014)'s work on e-platforms. The argument is that public administrations should not adopt a narrow vision of what "smart" means by simply considering the adoption of ICTs, as the ultimate goal smart cities have to achieve. According to this branch of literature, the cities of the future should favour city dwellers' wellbeing and sustainability, and ICTs should remain a simple mean to meet these ends.

Together with this branch of literature, there is a critical literature discussing the concrete technologies and challenges at stake when referring to the buzzword "Big Data" (Chen and Zhang 2014; Sivarajah et al. 2017). Without questioning the fact that we entered the Big Data era, a collective of 21 American researchers from public and private institutions issued a white paper detailing what the analysis and practical use of large volumes of data really require (Agrawal et al. 2012). This contribution also insists on the progresses Big Data has already brought in scientific fields as well as in industrial areas and urban planning. In this line, a recent article argue for the need of adapting innovative cluster policies to the challenges of the "Fourth Industrial Revolution" including Big Data's challenges (Park 2018). On a different note, drawing on Donoho's critical views, Sha and Carotti-Sha (2016) insist on the limits of Big Data as a "buzzword", since administrators and business circles often use it as a new and trendy word to speak about old technical issues. Together with other scholars (Kitchin et al. 2017), Sha and Carotti-Sha also argue that data volume matters less than the content and value of the information carried (Sha and Carotti-Sha 2016). Usefully, Batty (2016) clarifies the keyword by distinguishing 
between two issues: on one side, the access to new types of urban data that can change our perceptions about cities (e.g., semantic data from Social media, such as Twitter) and on the other side, traditional data that can easily become complex to handle when processed in mathematical models (e.g., traffic data).

The debunking approach is also developing regarding "AI". Administrators and business men sometimes use "AI" as another word for "data science" although it represents just a small part of it (Carmichael and Marron 2018) and, at the same time, it traditionally refers to a broader area of knowledge (Lungarella et al. 2007). In a report, McKinsey analysts consequently distinguish between "artificial narrow AI"-potential applications of $\mathrm{AI}$ in business and the public sector (i.e. transfer learning, reinforcement learning and deep learning neural networks) - which is the focus of their report, and "artificial general intelligence that could potentially perform any intellectual task a human being is capable of' (Chui et al. 2018). The relation between AI and Big Data is not straightforward, but the two concepts co-occur when referring to learning techniques. Indeed, learning techniques improve when trained on vast amounts of data. Given the growing amount of data available on urban systems, city engineers unsurprisingly consider the adoption of AI techniques for urban management. As we show in the next subsection, not only does existing literature question the effects of the Big Data and AI trends on the society but it sometimes simultaneously considers their effects on the academic world. Ethical and practical risks of relying on Big data and AI technologies are also under study (Kitchin 2016; Boyd and Crawford 2012). Together with the risks for errors when used for decision-making, there are issues regarding the use of private and personal data on individuals to administrate and monitor urban systems (Thatcher 2014; Polonetsky and Tene 2013). The risks for unemployment, accidents and catastrophes when used in robotics and autonomous devices (drones, vehicles) are also the topic of much research (Turchin and Denkenberger 2018; Stilgoe 2017). Less studied so far is the potential for important transformations in research practices and for competitions between approaches. The next sub-section focuses on the effects of Big Data and AI on urban research. It shows that so far, this issue has been mainly addressed by urban researchers trying to interpret and influence changes at work.

\subsection{The Big Data and AI era in urban research}

Anderson's provocative claim that "the data deluge makes the scientific method obsolete" has prompted defensive reactions in the fields of social science, human geography, urban planning and urban research (González-Bailón 2013; Graham and Shelton 2013; Batty 2013; Thatcher 2014; Bettencourt 2014; Kitchin 2016). For GonzálezBailón (2013), the increase of data in social science strengthens the need for theory. Focussing on human geography only, Graham and Shelton (2013) consider how Big Spatial Data can change the discipline of geography. Drawing upon Anderson's claim, they ask: "What do Big Data mean for how we do research and create knowledge?" Notwithstanding the challenge for "conventional notions and practices of 'hard science' including to the field of Geographical Information Science" (GIS), Graham and Shelton focus more precisely on the risk for a new quantitative and positivist turn in geography. To avoid its pitfalls, they insist on the need for critical geography and the adoption of critical views regarding Big Data. Thatcher's view (2014) is very close to theirs. He draws an interesting parallel between the advent of Spatial Big Data in the 2010s and the advent of GIS in the 1990s. According to him, a similar threat has hung over the GIS field in the 1990s, i.e., a risk for forgetting theory at the benefit of technical achievements. He recalls that, unexpectedly, GIS specialists achieved a "hard work of theory" to unravel the relation between the specific technological form and the knowledge produced. It gave birth to GIS and society, qualitative GIS, and critical GIS. According to Thatcher, a similar move toward theory is required to deal with the advent of Big Spatial Data. Addressing the issue for urban studies, Batty also rejects Anderson's claim (Batty 2013). He particularly rejects Anderson's idea that, in the Big Data era, "correlation supersedes causation, and science can advance even without coherent models, unified theories, or really any mechanistic explanation at all". According to Batty, this argument is not valid: "In terms of cities and 
their functioning, the search for correlations would be something of a diversion, for what we need to look for in Big Data can only ever be discovered through the lens of theory."

Paradoxically, most authors seem to consider that, instead of making theory obsolete, the advent of Big Data calls for more theory. Interestingly, this claim for theory also appears in the discourse of 'hard science' specialists such as, for instance, Korukonda (2007), who advocates for more theory in the technical and applied area of Data Mining. By calling for more theory, scholars tend to favour the idea of taking into account "Big Data" as a new object of study and an opportunity in their research field. As a result, they give a description of the kind of new questions to address in the frame of social science, human geography, urban studies, computer science and civil engineering (Lobo et al. 2020; Zheng et al. 2014; Pan et al. 2016; Gao et al. 2019). Among these scholars, Batty not only considers the challenge of Big Data for theory, but also the challenge of Big Data for the scientific practice of quantitative modelling (Batty 2013; Batty 2014). Drawing upon his experience in the field of urban modelling, Batty (2014) is confident that Big Data will not make urban models obsolete. The main reason for that is that urban models such as landuse models are long-term models, whereas Big Urban Data is mainly about real-time data allowing for short term observations. It does not mean these data are worthless but analysing them will serve to answer new questions. As an illustration, Batty (2013) gives the example of the Oyster card data from the London subway that require the development of new models to be analysed. Regarding this last issue, Batty does not seem exactly on the same line as Bettencourt (2014) and Kitchin (2016).

According to Bettencourt (2014), modern technologies (such as deep learning techniques) can help solving difficult and important problems "essentially without theory and this is the (potential) miracle of Big Data in cities". However, when dealing with problems arising at longer temporal or larger scale, Bettencourt considers that the resulting complexity still require developing models of human behaviour. In this last regard, he agrees with Kandt and Batty (2021). As Bettencourt, Kitchin (2016) moderates Anderson's claim without rejecting it entirely. Instead of adopting Anderson's extreme approach to "Urban Science", Kitchin advocates for "data-driven science that seeks to hold to the tenets of the scientific method, but seeks to generate hypotheses and insights 'born from the data' rather than "born from the theory". What Bettencourt and Kitchin do not reject is that modern AI technologies and Big Data will help solving some urban and planning problems better than they were before. Considering the time and spatial scales of a range of urban issues, Bettencourt distinguishes between (1) simple issues, such as, transportation, fire, epidemics, traffic, water, trash collection, and (2) complex issues, such as, education, poverty, public housing, employment and economic development. According to him, the data-driven logic will help turning some of the first issues into simple problems and solve them.

To our view, successes of data-driven methods over theory-driven ones and scenarios of these replacements have been under-studied and under-documented so far. In this article, we address this issue through a science studies' lens. According to us, the literature should not only seek to include a fourth helix, i.e. the civil society (Borkowska and Osborne, 2018), within Etzkowitz and Leydesdorff's (2000) classical model of innovation (1. government, 2. academia, 3. industry), but this literature should also put the current dynamics of the academic world under renewed study. Researchers used to play an important part in the administration and monitoring of urban systems by working with public services and private companies owing the infrastructures. With the advent of Big Spatial Data owned by ICTs companies (new private players), what is the place of public researchers? Are not they threatened both by the technical challenges related to the processing of Big Data, and by the commercial nature of these data? Since Microsoft and IBM are developing their own Urban Computing teams, is there a risk for public researchers to be left behind and for public administration to be obliged to work with private researchers or to contract with new geospatial companies, such as Waze to manage their infrastructures (Courmont 2018)? Given these novel interrogations, we consider there is a need for refocussing on the academia helix and investigate first, its internal transformation, and second, the evolution of its relations with the three other helices, 
namely the political world, the economic world and the social world. In this article, we want to address the first issue, academia's internal transformation in the Big Data and AI era. To do so, we conducted a set of interviews that led us, for the purpose of this article, to focus on two fields of research: the transportation field and the water field, and two subfields: traffic flow studies and water quality studies.

\section{Interviews, guiding questions and bibliometric method}

\subsection{Interviews and cases studies}

To investigate the issues raised in the academic world by the advent of the Big Data and AI turn in urban management, we led two series of interviews between January and July 2018.

The first series was organised in the Eastern part of the Paris area with eleven scholars, from various applied disciplines, working in relation with a civil engineering school: three applied mathematicians, three computer scientists, two economists, one quantitative geographer, and two urban water studies' specialists. The second series was organised in Edinburgh during the launch of the Data Driven Innovation (DDI) Programme, which is part of the City Region Deal aiming to "help establish the region as the data capital of Europe". This programme attempts to realise its goals by helping organisations and individuals to connect to research and development in the generation, storage, analysis and use of various forms of data. In addition to attending meetings and co-organizing a round table with university officials regarding this issue, we conducted five interviews. We interviewed (1) the new centre in data science and IA's head, (2) the Data Innovation Director of the University of Edinburgh, (3) a member of the Innovation and Future Team at the City Council, (4) a co-founder of the Edinburgh Living Lab and finally, (5) a senior IT at the UBDC (Urban Big Data Center) of Glasgow University.

The interview protocol varied according to the setting. In Paris, we mainly focussed on research practices. We asked scholars their view on the possible competition between "Big Data" approaches and "modelling" approaches. Then, we asked them if they had specific examples in mind of competition between a deterministic model and a data-driven solution in any field of urban management. After that, we talked about their research practices, their possible link with "urban modelling" (in the broadest sense including all type of quantitative modelling) and with "Big Data" (in the broadest sense including all data-driven approaches). To finish, we discussed about their career. To get a comprehensive view of their position in the academic world, we invited them to comment a map of their coauthorship network. Since the interviews were semi-directed, some peripheral themes emerged and proved to be important: How to cope with the evolving needs in terms of training offers? How to deal with the gap between company and public administration's needs and research objectives? What are the true research challenges? Indeed, one of the most commonly shared idea was that most companies and public administration's needs do not represent a research challenge. According to the interviewed scholars, despite the socalled "deluge" of urban data, the scientific knowledge and the techniques necessary to meet most company and public administration's needs already exist.

As expected, these interviews highlighted some interesting cases of studies related to contemporary issues in urban systems' management. For this article, we relate two opposed cases: one case linked to traffic management and the other case linked to urban water management. The first case exemplify the possibility of hybridisation between physically inspired models and data-driven approaches and the second case, on the contrary, illustrate a case of competition between the two. We discussed the first case with two of the interviewed: an applied mathematician and a computer scientist; and we discussed the second case with two urban water studies' specialists.

The first case deals with issues of traffic simulation and real-time traffic prediction. Two of our interviewees mentioned the example of a $\mathrm{PhD}$ thesis (they have been involved in) proposing to combine stochastics methods and deterministic models. In this research, there was a wish to improve existing models of traffic simulation that lie upon determinist laws by taking into account real-time traffic data. In the resulting $\mathrm{PhD}$ thesis (Sainct 2016), pure 
statistical approaches based on learning algorithms are discarded in the following way: "It should be noted that a purely statistical learning approach by time-series prediction, can in some cases give satisfactory results. On the other hand, this approach lives in a purely numerical universe. Without checking the accuracy of the sensors' physical position in relation to the reference frame, it can, therefore, learn an imaginary physics that has its own combinatorics and its repetitions, but has no longer any connection with reality." Yet, the thesis' conclusion opens with the perspective of testing neural networks to improve traffic prediction from real-time data. According to the former PhD student: "working with real data is essential to understand traffic issues. It is through observation, and through testing, that one realizes that, although relatively frequent, the drop in capacity is a phenomenon that cannot be reproduced with the LWR model [classic model of traffic simulation]." He thus recognizes the weakness of classic models for real-time prediction and specifies that, to his knowledge, wishing to combine deterministic models and stochastic methods is novel and not yet conclusive. What is interesting in this example is that it led the former $\mathrm{PhD}$ student to work both with applied mathematician specialised in traffic models and with computer scientists specialised in learning methods, and that, additionally, he devoted part of his doctoral time on the design of a traffic monitoring application commercialised by a French multinational company. This example suggests that, at least for traffic flow issues, there are scholars looking for ways of combining operators' expectations, data-driven approaches and improvements of deterministic models (that try to describe the dynamics of transportation systems with physical laws). However, there might not be a majority of them and we might heard of classic models being abandoned because of their mismatch with reality. To get a more complete view of current dynamics in this research area, we then propose to explore its recent evolutions with bibliometric analyses.

The second case testifies from a conflict between classic modelling and real-time monitoring in the applied area of urban water research. This is the story of ProSe, a deterministic model designed to simulate the evolving water quality of a hydrographic network. Since 1995, the Siaap (a French public institution), uses this model to evaluate the impact of the Paris Region wastewater treatment system on its receiving water body: the Seine and Marne rivers (Laborie et al. 2016). As explained by Laborie et al. (2016), the Siapp uses this model "as an operational tool to assist in decision-making, such as wastewater routing choices during partial or complete WWTP stoppage." However, in recent years, Siaap experts and engineers began to highlight some limitations of the model regarding their actual needs. During our interviews, we discussed this specific case with water studies' specialists who conducted a fieldwork comparing this French case with a foreign one. In an article derived from their research, they focus on "the trade-off between scientific complexity and 'usability' of scientific knowledge and tools to support management, policy and planning decisions" (Chong et al. 2017). At one point in their article, they explain that Siaap engineers are currently "moving towards artificial intelligence and real-time control methods and are considering replacing the model with statistical techniques for daily operations (Siaap representative, 10 March 2016)." According to our interviews, the reasons for this evolution are that ProSe was primarily designed for research purposes and that its designers are very keen to protect their independence and objectivity against operational needs. In addition, these scientists do not wish to include AI and real-time methods in their model because they consider these methods to relate to technical rather than scientific aspects. To solve this issue, Siaap representatives are looking for new collaborations. In particular, they intend to develop a cooperation with AI specialists located in Montréal (Canada). Even if it does not mean that the Siaap will abandon the model at the end, this story shows that there exist different views on models' role and on the scientific nature of AI and real-time control methods. Although some scholars, such as Betancourt (2014), consider useful and promising for both science and society to apply AI and real-time control methods to urban issues, other scholars perceive these methods as outside of their research scope since they do not bring any concrete knowledge on the physical aspects of the system's dynamics. As explained by a computer scientist we interviewed, "since about 2012, deep learning has taken a step up 
and made it possible to be ignorant on a subject. To have a well-functioning neural network, it only takes a little experience and the results explode the results we had before. But there is a controversy between researchers as to whether it is still science" (Computer scientist, 16 January 2018).

From these particular cases, we note that among existing positions, some are open to the potential for hybridization between new and old methods, while others see these approaches as opposed. According to the observations of Chong et al. (2017), it is actually common for an opposition to emerge between operational issues on the one hand, and research issues on the other. Beyond these questions of perception, there is the wariness of fad phenomena. When all funding and research policies turn to a new hot topic, schools and universities are encouraged to launch doctoral projects and new training courses on this topic to attract funds and students. These strategies are risky and, from the point of view of the sociologist and historian Yves Gingras, who calls for mistrust of the current enthusiasm for AI (Gingras 2018), they can be harmful to science. During the interviews we conducted in the French school of civil engineering, researchers expressed such mistrust. These researchers remember the recent trend for financial mathematics and want to be cautious with the current craze for data science. While they consider important to develop their training offer in statistics, they do not want to transform the all curriculum according to the current interest for data-driven approaches: "The fact that we now have access to more data than before does not justify a change in curriculum. We will certainly boost the statistics and make the student work on "reverse problems", so that they can understand when and how they can use more data in their work but that is all" (Applied mathematician, 9 January 2018). On the other hand, at the University of Edinburgh, we observed a real willingness to develop data science courses, explained both by the university's historical strengths in AI and robotics and by the windfall effect of the dataoriented City Deal.

Without seeking to analyse the precise contents of the bibliographic sets under study, the rest of this article seeks to quantify the penetration of AI and big data methods in scientific research and production (1) on water and transportation studies and (2) on water quality and traffic flow studies. In addition, we try to determine to what extent specialists in AI and Big Data methods tend to be interested in water quality and traffic issues. Indeed, it may very well happen that technique-oriented researchers end up taking up thematised subjects and proposing solutions that compete with existing solutions. In this case, these researchers may challenge traditional and expert communities or, on the contrary, they may be able to complement one another and work together. The study of the confrontation between phoneticians and acousticians during the 1970s, which led to the emergence of speech sciences analysed by Grossetti and Boë (2008), gives such an example of success of one community over the other. In the balance of this article, we conduct an exploratory analysis using bibliometric data to study the dynamics that are developing for the two particular cases we identified above.

\subsection{The guiding questions and the bibliometric approach}

Drawing upon the previous cases, we formulate two research questions that we propose to address to explore current transportation and water research dynamics:

- Do scholars traditionally related to these research fields tend to improve their classic models by taking into account the growing amount of real-time data available on transportation and water systems?

- Do academics specialized in data handling tend to be more and more interested in the opportunity of applying AI and Big Data technologies to the management of these two urban systems?

Of course, it is challenging to give a categorical answer to these two questions since some scholars can adopt one strategy and other scholars, from the same field, can adopt a different one. This possibility legitimise our choice of distinguishing between two levels: the level of the field and that of the research question. In doing so, it can also be observed to what extent the dynamics observed at the level of the research question coincide with that of the field. The interviews led in Paris and Edinburgh suggested indeed that a variety 
of strategies is still prevalent at this stage. The difference in approach encountered during our interviews in Paris concerning the example of traffic prediction and that of water quality guided us in the choice to focus the bibliometric study (1) on the fields of transportation and water and (2) on these two specific research questions within these fields. The two previously documented cases are not sufficient to generalise, whereas the bibliometric approach offers a means of highlighting overall trends. Even if it deprives us of the nuances accessible through interviews, it allows us to have a macroscopic view of current dynamics. Thus, the interviews made it possible to compare points of view and collect examples with the help of which we were able to refine our research questions and the research protocol used for the bibliometric analysis. The interviews then revealed once again to be a great support for interpreting and enriching some of the quantitative observations.

To conduct this bibliometric analysis, we propose to rely on the content of the Web of Science (WoS) database. The first reason for this choice comes from the precise classification of the journals indexed in the WoS Core Collection database at the subdiscipline level. All the 18,000 journals and 180,000 proceedings indexed are categorised according to one or several of the 252 distinct scientific categories among which there are "transportation" and "water resources". This categorisation applies to journals and, therefore, makes it possible to work on sets which are stable over time and whose internal dynamics can be studied by means of a keyword query.

As explained in detail by Huang et al (2015), search strategies are multiple in bibliometrics and all have their own strength and weaknesses. In the case of research on the scientific production in the Big Data area, Huang et al. demonstrate the relevance of using a Boolean search methodology. The demonstration is made using the content of the Web of Science and by including the index of Conferences Proceedings in the search as we propose to do. In addition to relying on the methodological proposal of Huang et al., we also take up the lexical search strategy adopted by Cardon et al. (2018), informed by experts in artificial intelligence, to distinguish between "logic-based AI" and "connexionnist AI" in the Web of Science. Insofar as we remobilise the lexical search strategies of Huang et $a l$. and Cardon et al., whose development and validation were carried out using the content of the Web of Science, it seems relevant to rely on the same bibliographical database as these authors to carry out our analysis.

To estimate the penetration of data driven approaches (1) in the traditional fields of transport and water research and (2) within the research questions of traffic flow and water quality (1st research question), we select: (1) the publications published in the journals belonging to these two fields, and (2) two sets of publications focussing on these two issues. Then, we measure, (1) in each set of journals and (2) in each sets of publications, the evolving number of publications referring to AI, Big Data and other Machine Learning keywords in their titles, abstracts and list of keywords.

To estimate the interest of academics specialized in data handling for transportation and water issues ( $2^{\text {nd }}$ research question), we measure the evolving share of publications linked to the "Computer Science" WoS subject area compared to others WoS subject area within the research questions of traffic flow and water quality. Additionally we apply lexical analyses' tools to monitor the evolution of the scientific vocabulary used regarding these two research questions.

Laying upon the result of this search, if we observe that the share of AI and Big Data publications increases in traditional fields, while computer science journals tend to publish a growing number of articles referring to the keywords of the two urban issues, it would suggest that a significant change is at work. Three scenarios could be possible from this observation, among which we consider it is too soon to settle. Indeed, this situation would mean that we could equally assist in the following years to:

$\circ$ The hybridisation between the traditional sub-field of research and computational, AI, or Big Data research.

$\circ$ The peaceful and neutral co-existence of the traditional sub-field of research and the development of novel computational approaches to deal with the research question among a different research community without any merging process. 
- The confrontation between classic and data-driven approaches with one approach (and research community) likely to prevail over the other.

Our observations could also point out that a dynamic is at work only in the traditional sub-fields or only on the computational research side. It could also reveal that the dynamics at work at the level of the research question (traffic flow and/or water quality) diverges from that of the corresponding fields (transportation and/or water). It may also be that no significant change emerges, which would suggest that so far, the transformation of urban management has no significant effect on research production dynamics regarding these issues and their associated fields. Finally, it is possible that the dynamics observed in one of the research sub-domains and urban issue differ from those observed in the other subdomain and issue.

This possible heterogeneity would lead to nuance the discourses seeking to generalise the probable effects of Big Data and AI on the field of urban modelling and this would confirm the interest of carrying out specific analyses per urban issue and urban field, following on from the exploratory analyses proposed here.

\section{Research dynamics in urban transportation and water systems}

\subsection{Research dynamics in transportation and water studies}

Transportation and water studies are both interdisciplinary research fields that are relatively autonomous from the academic disciplines they originate from. Transportation research mixes knowledge from engineering, operation research, ergonomics, as well as automation and control systems whereas water research mixes environmental, engineering, ecological, meteorological and agricultural knowledge. Journals, conferences, academic departments and job positions entirely dedicated to these fields testify from their relative autonomy.

To monitor the evolving part of researches taking into account AI and Big Data approaches in these two fields, we rely on the categories available in the WoS database. In the Wos database, every journals, books and conferences are associated to at least one scientific category among 252 . Some titles can belong to several categories since their content might straddle multiple categories.

At the beginning of January 2021, the transportation category includes 207,472 publications derived from 1598 journals, 135 books and 1509 meetings. They have been published between 1956 and 2021. On the same day ${ }^{1}$, the water resources category includes 380,133 publications derived from 1000 journals, 114 books and 1822 meetings. They have been published between 1965 and 2021. To monitor the evolution of AI and Big Data approaches in these two fields, we rely on two queries that propose various sets of keywords to retrieve AI and Big Data publications in the WoS database (Huang et al. 2015; Cardon et al. 2018). In the WoS Core Collection database, the keywords are searched in the title, the abstract and the list of keywords (both the authors' keywords and the Keyword Plus) of the publications.

Huang et al. (2015) propose five search strategies among which two lexical queries (Table 1). In Huang et al.'s publication, to reduce the noise ratio, the second lexical query is restricted by an additional set of specific keywords such as "Cloud Comput*" or "Data Min*" or "Analytic*", that need to co-occur with "Big Data" keywords. In our research, we consider this additional set of keywords is not relevant since, by searching "Big Data" publications in transportation and water resources WoS categories, we do not risk to include as much off-topic publications as if we were searching in the entire WoS Core Collection database.

To retrieve Big Data researches, we thus decide to combine the core lexical query with the first part of the expanded lexical query proposed by Huang et al. (Table 1). By combining these two queries, we obtain 83,741 publications published between 1960 and 2021.

\footnotetext{
${ }^{1}$ 2021-01-10 (ISO date format)
} 


\begin{tabular}{|c|l|ll|}
\hline 1 & $\begin{array}{l}\text { Core } \\
\text { lexical } \\
\text { query }\end{array}$ & $\begin{array}{l}\text { TS = ("Big Data*" OR Bigdata* OR "MapReduce*" OR "Map\$Reduce*" OR } \\
\text { Hadoop* OR Hbase OR "No SQL" OR “NoSQL" OR "NoSQL Database" OR } \\
\text { Newsql) }\end{array}$ \\
\hline 2 & $\begin{array}{l}\text { Expanded } \\
\text { lexical } \\
\text { query }\end{array}$ & $\begin{array}{l}\text { TS = ((Big Near/1 Data or Huge Near/1 Data) or "Massive Data" or "Data } \\
\text { Lake" or "Massive Information" or "Huge Information" or "Big } \\
\text { Information" or "Large-scale Data*" or "Largescale Data*" or Petabyte or } \\
\text { Exabyte or Zettabyte or "Semi-Structured Data" or "Semistructured Data" } \\
\text { or "Unstructured Data") }\end{array}$ \\
\hline
\end{tabular}

Table 1. Lexical queries used to retrieve Big Data researches (Source: Huang et al. 2015)

Retracing the history of artificial intelligence, Cardon et al. (2018) propose a way to distinguish between traditional AI, also called "logic-based AI" that was dominant from the 1980 s to the beginning of the 2000s, from "connexionnist AI" that is the form of AI mainly relying on artificial neural networks and deep learning techniques. Table 2 indicates the content of these two queries.

\begin{tabular}{|c|c|c|}
\hline 1 & $\begin{array}{l}\text { Connexionnist } \\
\text { Al lexical query }\end{array}$ & 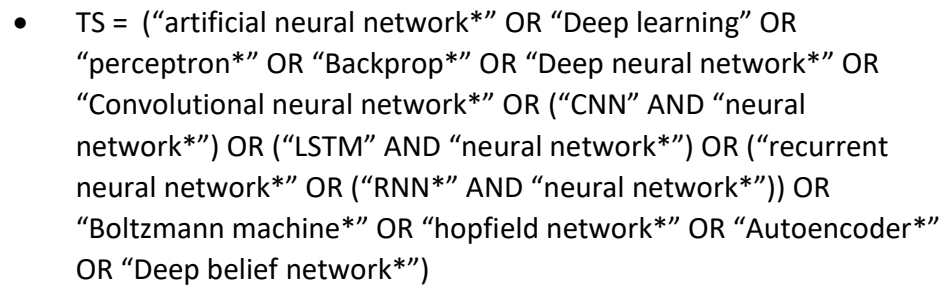 \\
\hline 2 & $\begin{array}{l}\text { Logic Based } \mathrm{Al} \\
\text { lexical query }\end{array}$ & $\begin{array}{l}\text { - TS = ("knowledge representation*" OR "expert system*" OR } \\
\text { "knowledge based system*" OR "inference engine*" OR "search } \\
\text { tree*" OR "minimax" OR "tree search" OR "Logic programming" OR } \\
\text { "theorem prover*" OR ("planning" AND "logic") OR "logic } \\
\text { programming" OR "lisp" OR "prolog" OR "deductive database*" OR } \\
\text { "nonmonotonic reasoning*") }\end{array}$ \\
\hline
\end{tabular}

Table 2. Lexical queries used to retrieve AI researches (Source: Cardon et al. 2018)

To make the Connexionist AI lexical query more up-to-date, we deliberately add the results of the following sub-query:

TS = ("adversarial neural network*" OR "generative adversarial network*" OR ("ANN\$" AND "neural network*") OR ("GAN\$" AND "neural network*")).

Adversarial neural networks are a class of artificial intelligence algorithms used in unsupervised machine learning and implemented by a system of two neural networks. In 2014, Goodfellow et al. introduced them for estimating generative models via an adversarial process (Goodfellow et al. 2014). By adding the abbreviation "ANN" to the Connexionist AI lexical query, we both include publications referring to "Artificial Neural Network" and "Adversarial Neural Network", therefore, improving the results of Cardon's original query. Combining Cardon's Connexionnist AI lexical query and our additional terms, we obtain 238,641 publications published between 1958 and 2021. In addition, Cardon's Logic Based AI lexical query returns 77,681 publications published between 1935 and 2021.

As we pointed out in Section 2.1, AI techniques are only one subset of the techniques used to deal with vast amount of real-time data. Since there are learning techniques that might not be considered as AI techniques, we consider a last lexical query. Drawing upon the retrieval work of Rincon-Patino et al. as well as the content of the "Machine learning" Wikipedia web page ${ }^{3}$, we come up with the following proposal (Rincon-Patino et al. 2018):

TS = ("Machine* Learn*" OR "Support Vector Machine\$" OR "Support Vector Network\$" OR "Random Forest\$" OR "Genetic Algorithm\$" OR "Bayes* Network\$" OR "belief network\$" OR

\footnotetext{
${ }^{2}$ Here, we propose a slightly improved version of Huang et al.'s query since we have decided to take into account Kalantari et al., 2017 suggestions regarding the use of wildcards.

${ }^{3}$ URL: https://en.wikipedia.org/wiki/Machine_learning, retrieved the 27/02/2019
} 
"directed acyclic graphic*" OR "supervised learn*" OR "semi\$supervised learn*" OR "unsupervised learn*" OR "reinforcement learn*" OR "turing learn*")

This last lexical query returns 426,386 publications published between 1946 and 2021. In what follows, this query will be named "Machine Learning, else" to indicate the fact that other Machine Learning publications are already taken into account in the Big Data and AI corpus of publications. Moreover, in what follows, we only consider the part of the Machine Learning set that is not included in the Big Data and AI sets. This part includes 359,081 publications. As we can observe in Figure 1, Big Data, AI (Connexionist and Logic Based) and other Machine Learning corpus of publications are only partially overlapping. One reason for this relatively small overlap can be that we only search in the titles, abstracts and keywords of the publications. However, it might also be the sign that the type of scientific contributions of each set is significantly different, which justifies treating them separately.

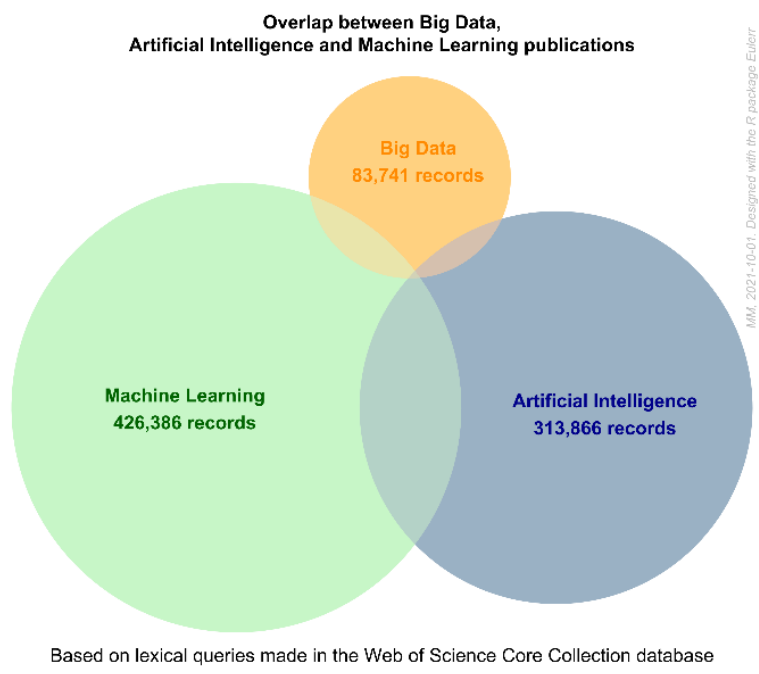

Figure 1. Overlap between Big Data, AI and Machine Learning corpus of publications

Figure 2 displays the annual number of Big Data, Logic Based AI, Connexionist AI and Other Machine Learning publications in both the transportation and water resources WoS Categories.

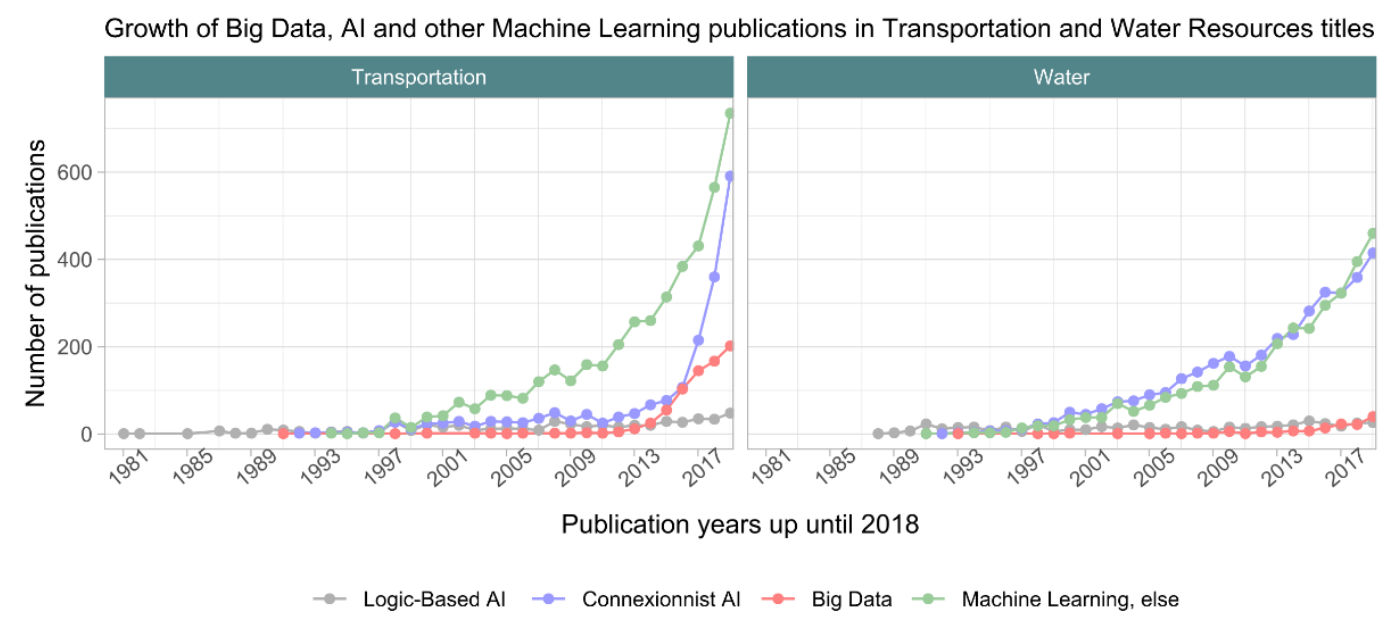

Indexes: SCI-EXPANDED, SSCI, A\&HCI, CPCI-S, CPCI-SSH, ESCI. Web of Science Core Collection. MM, 2021-01-11

Figure 2. Growth of Big Data, AI and other Machine Learning publications in Transportation and Water Resources titles 
We observe that Machine Learning keywords tend to be increasingly used since the 2000 s in both transportation and water resources' journals. Since the 2000s, Connectionist keywords have been as much used as Machine Learning keywords in water resources journals, but not in transportation journals. Connectionist keywords only developed in transportation journals after 2012 together with Big Data keywords. On the contrary, Big Data keywords do not seem to attract much interest in water resources journals. Moreover, in both transportation and water journals, Logic Based AI has never been much popular. In Figure 2 and following (Figures 3, 4, and 5), we only represent data from publications released before January 1, 2019. Indeed, if the numbers of publications for 2019 and 2020 were represented, a decrease in the absolute volume would be observed simply, because the indexing of data in the Web of Science is not yet complete for those years.

Drawing in Figure 2, we can answer the first part of our first guiding question. Indeed, these evolutions suggest that Machine Learning and AI techniques are attracting interest in both fields and that authors publishing in specialized journals in transportation and hydrology are importing and testing these techniques on their classical research problems. To verify if, conversely, transportation and water issues are attracting a growing interest among mathematicians, physicists and computer scientists specialised in Big Data and AI techniques, we propose to focus on two specific issues: traffic flow and water quality. The choice of these issues is justified by the qualitative knowledge we collected about them during the interviews' stage of our research.

\subsection{Research dynamics in traffic studies and water quality studies}

To monitor the interest for urban issues among Big Data and AI specialists, we consider the example of Traffic Flow and Water Quality studies. Drawing upon the interviews described in section 3.1, we know that both issues can be addressed using classical modelling method as well as learning techniques applied on real-time data. To select comparable set of publications associated to the two topics, we adopt a common list of action verbs "forecast", "model", "predict", "simulate" and "estimate", that we associate with keywords corresponding to the specific issues at stake. Table 3 details the resulting lexical queries that we apply for extracting WoS Core Collection publications in Traffic Flow and Water Quality studies.

\begin{tabular}{|l|l|l|}
\hline 1 & $\begin{array}{l}\text { Traffic } \\
\text { flow } \\
\text { studies }\end{array}$ & $\begin{array}{l}\text { TS=(("traffic flow*") AND (forecast* OR model* OR predict* OR simul* OR } \\
\text { estimat*) AND (highway OR freeway OR motorway OR lane OR road OR street OR } \\
\text { "urban network*" OR transportation)) }\end{array}$ \\
\hline 2 & $\begin{array}{l}\text { Water } \\
\text { Quality } \\
\text { studies }\end{array}$ & $\begin{array}{l}\text { TS=((("water quality") OR (river NEAR/1 quality)) AND (forecast* OR predict* OR } \\
\text { model* OR simul* OR estimat*) AND (phosphorus OR nitrogen OR phytoplankton)) }\end{array}$ \\
\hline
\end{tabular}

Table 3. Lexical queries used to retrieve traffic flow and water quality studies

The resulting number of publications is similar for the two issues: 9303 publications about traffic flow and 10,379 publications about water quality. In addition, the annual number of publications registered in the WoS database is similar for the two sets, which make them quite comparable (Figure 3).

To monitor the dynamics of these two research issues, we adopt three strategies. First, we monitor the evolution of AI and Big Data keywords in the two sets. Second, we measure the number of traffic flow and water quality publications in computer science, mathematics and physics titles. Third, using Iramuteq software (Ratinaud 2008), we perform an AFC analysis to detect the most significant words of the publications' abstracts before and after 2012. In addition to present the quantitative results of this bibliometric study, we use the content of our interviews to illustrate and qualify observed dynamics and discuss possible outcomes.

Big Data, AI and other Machine Learning keywords are considerably developing in Traffic Flow studies since 2005. Whereas Machine Learning keywords are much more frequent than AI and Big Data keywords in transportation journals (Figure 2), they are used almost as much as AI and Big Data keywords in Traffic Flow studies. Here, it is important to understand that the records are not limited to transportation journals. In Water Quality 
studies, the use of Connectionist keywords has developed around 2013 but has been declining onwards (Figure 2).

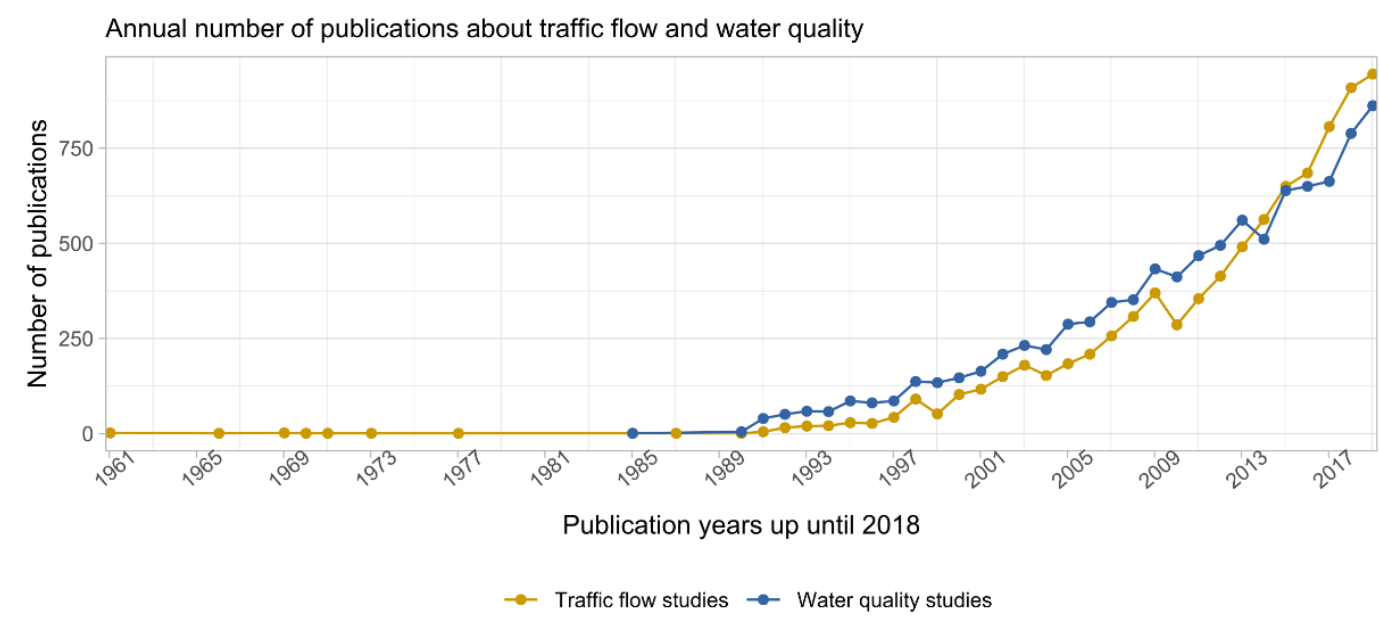

Indexes: SCI-EXPANDED, SSCI, A\&HCI, CPCI-S, CPCI-SSH, ESCI. Web of Science Core Collection. MM, 2021-01-11

Figure 3. Growth of traffic flow and water quality publications in the WoS Core Collection

Machine Learning keywords were used less than Connectionist keywords until 2018. In 2018, Machine Learning keywords were used in 26 Water Quality publications. Even, if it is more than ever before in this research area, it is still half the number of time these keywords are used in Traffic Flow studies. Corroborating the infrequent use of Big Data keywords in water resources journals, we observe Big Data keywords are almost never used in Water Quality studies. Logic-Based AI has never been much used in both Traffic Flow and Water Quality studies. Whereas there are almost the same number of Machine Learning publications in transportation and water resources journals, and there are more Connectionist publications in water resources journals than in transportation journals (Figure 2), we observe an inverse situation between Traffic Flow and Water Quality studies (Figure 4). So far, Traffic Flow is an issue leading to more AI and Machine Learning publications than Water Quality.

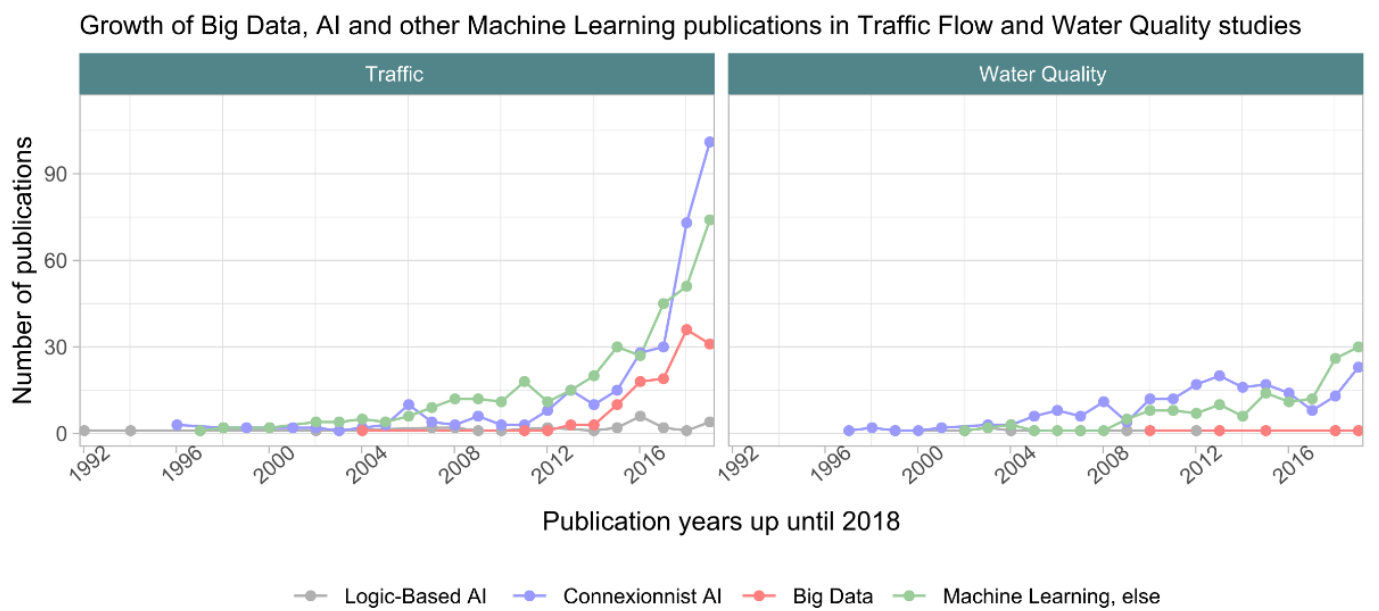

Indexes: SCI-EXPANDED, SSCI, A\&HCI, CPCI-S, CPCI-SSH, ESCI. Web of Science Core Collection. MM, 2021-01-11

Figure 4. Growth of Big Data, AI and other Machine Learning publications in Traffic Flow and Water Quality studies

Traffic Flow is an issue that first made its appearance in mathematics journals in the 1960s. From there, the share of Traffic Flow publications in non-transportation journals has always been significant. In Figure 5, we observe that the number of Traffic Flow 
publications in journals of physics exceeded the number of Traffic Flow publications in mathematics journals from the 1990s onwards. Nagel and Schreckenberg publish their seminal contribution "A cellular automaton model for freeway traffic" in 1992 in Journal de Physique and, from 1991, Physica A issued 289 Traffic Flow publications. From the 2000s onwards, Traffic Flow publications in computer science titles started to exceed Traffic Flow publications in mathematics and physics journals. The gap is even more significant in 2009 and 2017. In 2017, the number of Traffic Flow publications in computer science journals culminates in more than 200 publications.

On the opposite, Water Quality has never been a frequent topic in mathematics, physics and computer science titles. In 2005, 2009, 2011, the topic appeared in about 20 mathematics and computer science publications but the number of Water Quality publications in these titles has continuously decreased since 2015. It suggests that, contrary to Traffic Flow, the topic does not attract professionals from modelling and prediction methods, or at least that it does not interest editorial boards of journals in mathematics, computer science and physics. Even if there is an operational interest for AI and Big Data methods to monitor water quality in urban systems (Adamala 2017), these results suggest that this interest does not translate into research dynamics. There could be various reasons for this lack of interest. Drawing on our interviews, we can think of three reasons. First, it might be that computer scientists, physicists and mathematicians have less access to water quality data than to traffic data. Second, it might be that the domain of validity of water quality models is bigger than traffic models' one (since vehicle's behaviour is more unpredictable than water's behaviour). Third, it might be that the water quality issue offers not enough novelty to justify a research article. As explained by a statistician we interviewed, "in data science, problems always have different characteristics that require reflection, but this reflection is not always interesting enough to be the subject of an article in our field. You cannot make a research article for every application case." (Statistician, 16 January 2018).

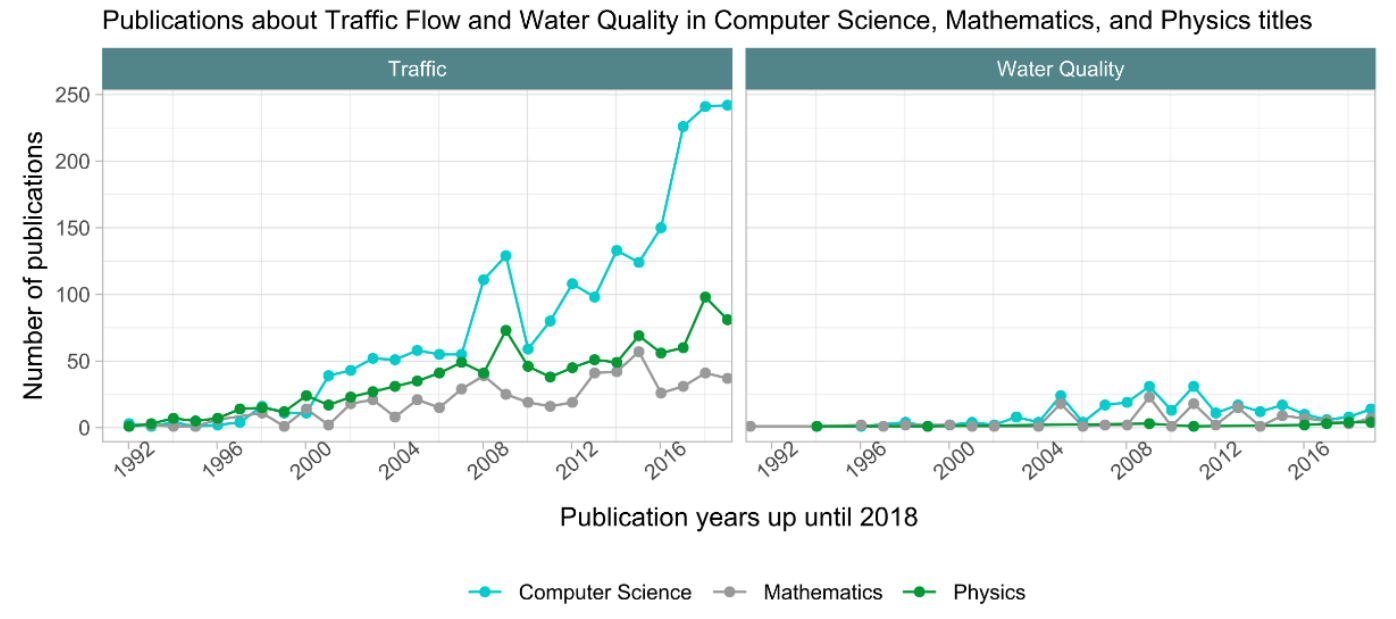

Indexes: SCI-EXPANDED, SSCI, A\&HCI, CPCI-S, CPCI-SSH, ESCI. Web of Science Core Collection. MM, 2021-01-12

Figure 5. Publications about Traffic Flow and Water Quality in Computer Science, Mathematics and Physics titles

To monitor the internal dynamics of the two issues under scrutiny, we perform a lexical analysis. Considering the content of the publications' abstracts, we are able to detect, ceteris paribus, the most typical words used before 2012 and after 2012 for each topic (Tables 4 and 5). The choice of 2012 as time limit is justified by the fact that AI and Big Data keywords considerably developed after this date in Traffic Flow studies (Figure 4). Therefore, we suspect the vocabulary used in Traffic Flow studies would significantly reflect the growing adoption of AI and Big Data techniques after 2012.

As expected, we notice that the word "deep" is one of the most significantly used words after 2012 in Traffic Flow studies contrary to the nominal group "cellular automaton". It 
suggests, in line with the assumptions of this work, that the physically inspired "cellular automaton" method is in the process of being replaced by "deep learning" methods to monitor and predict traffic flow. The word "model" is also typical of pre-2012 Traffic Flow studies, which suggest that, at least for traffic issues, we might assist to "the end of theory" announced by Anderson. However, if we look to other post-2012 words, we observe the acronym "MFD" together with an interest for new types of vehicles (autonomous vehicles, smart vehicles and bicycles). It suggest that, in addition to a novel consideration for smart mobility and bicycles, Traffic Flow studies are still focussing on the fundamental diagram. This diagram gives a relation between traffic flux and traffic density. Traffic operators use it to monitor urban congestion. In line with the example developed in 3.1, it seems that, so far, Traffic Flow research is integrating AI and Big Data techniques without abandoning classical approaches. To confirm this observation, we look at the evolution of the number of Traffic Flow publications in two important transportation journals: Transportation Research Part B and Transportation Research Part C. The difference between the two journals is topical: Part B focusses on physical models, whereas Part $\mathrm{C}$ focusses on new technologies. As shown in Figure 6, the number of traffic flow publications published in Part C increased in recent years, but the issue remained important in Part B. According to us, monitoring the evolving distribution of Traffic Flow publications between these two journals is a good way to track the research dynamics of the research area. Taking into account the evolving citation behaviour of the authors publishing in these two journals could also be an interesting way of following the current dynamics (analysing the evolving scope of their cited references).

\begin{tabular}{|l|l|}
\hline Typical words before 2012 & $\begin{array}{l}\text { Concentration; canyon; transition; cellular automaton; phase; highway; } \\
\text { model; ramp; freeway; flow; incident; AHS (automated highway system); } \\
\text { pollutant; computer }\end{array}$ \\
\hline $\begin{array}{l}\text { Typical words from 2012 } \\
\text { onwards }\end{array}$ & $\begin{array}{l}\text { Connect; propose; VSL (variable speed limit); vehicle; prediction; energy; } \\
\text { bicycle; autonomous; smart; electric; deep; consumption; mobility; MFD } \\
\text { (macroscopic fundamental diagram); cooperative }\end{array}$ \\
\hline
\end{tabular}

Table 4. Typical words used before and after 2012 in Traffic Flow studies

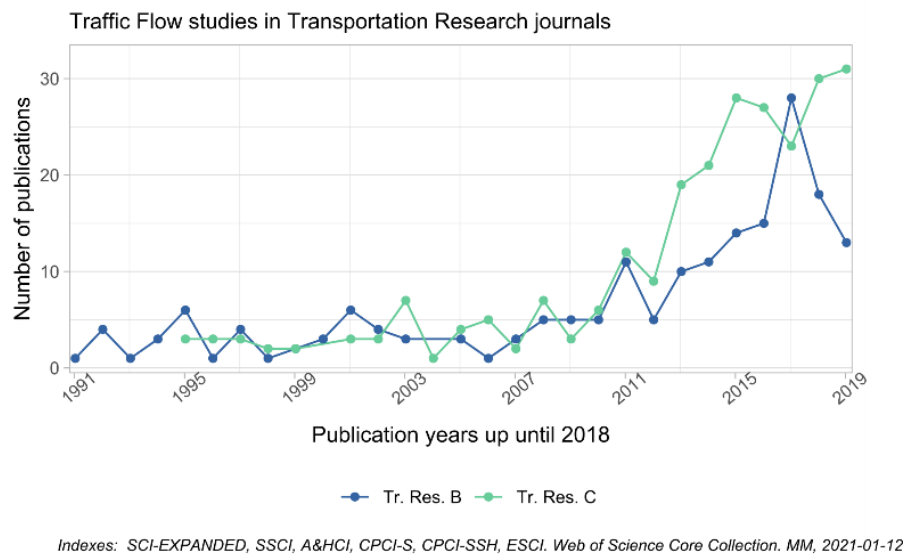

Figure 6. Traffic Flow studies in Transportation Research journals

As we could expect drawing in Figures 4 and 5, the lexical evolution observed in Water Quality studies does not allow identifying a change in research methods. The main difference seems to be a geographic difference since the words "China" and "TGR" (Three Gorges Reservoir) make their appearance after 2012. It suggest that Water Quality research has become an important issue in China in recent years. The word "scenario" which is a feature of modelling approach is one on the most typical words used after 2012, suggesting that learning techniques do not threaten modelling approaches in this research area. Once again, given the observations made in interviews, we can make the hypothesis that, so far, while learning techniques interest water operators, they do not modify research dynamics among Water Quality scholars. 
Figure 2 confirms that $\mathrm{AI}$ techniques are known and used for a long time in water research, but according to Figures 4 and 5, Water Quality does not appear to be an interesting issue for applying them, at least for research purpose. This difference between the trend observed at the level of the field and that observed at the level of the research question makes it possible to validate the principle of an investigation of research dynamics at several levels, and in particular at the finer level of the research question.

\begin{tabular}{|l|l|}
\hline Typical words before 2012 & $\begin{array}{l}\text { Manure; soil; ground; plot; NH (Ammonia Nitrogen); lagoon; litter; runoff; } \\
\text { mug; application; GIS; waste; poultry; deposition; compost }\end{array}$ \\
\hline $\begin{array}{l}\text { Typical words from 2012 } \\
\text { onwards }\end{array}$ & $\begin{array}{l}\text { Climate; China; TN (Total Nitrogen); driver; service; change; study; legacy; } \\
\text { future; TGR (Three Gorges Reservoir); scenario; switchgrass; mitigation; } \\
\text { Chl (Chlorophyll); stormwater }\end{array}$ \\
\hline
\end{tabular}

Table 5. Typical words used before and after 2012 in Water Quality studies

Given the results of this bibliometric analysis, we can establish that the answer to the second part of the first guiding question and to the second guiding question is not the same in the case of traffic research and water quality research. First, we observe a growing interest for AI and Big Data technologies within traffic flow studies, but not within water quality studies (Question 1, part 2). Second, we observe a growing interest for AI and Big Data technologies applied to traffic flow data in Computer Science, but not to water quality data (Question 2). Table 6 summarises these results.

\begin{tabular}{|l|c|c|}
\hline & Transportation and Traffic Flow & Water and Water Quality \\
\hline $\begin{array}{l}\text { Question 1: Penetration of data } \\
\text { driven approaches }\end{array}$ & Yes and yes & Yes and no \\
\hline $\begin{array}{l}\text { Question 2: Interest of academics } \\
\text { specialized in data handling for } \\
\text { urban issues }\end{array}$ & Yes & No \\
\hline
\end{tabular}

Table 6. Summary table of results

\section{Discussion}

This exploratory work suggests that the effects of the Big Data and AI turn in urban management vary according to urban issues. Focussing on Traffic Flow studies, we observed that AI, Big Data and Machine Learning keywords are increasingly used and that computer science titles are publishing a growing number of publications on the topic. On the opposite, computer science, mathematics and physics titles tend to publish little on Water Quality. Moreover, the use of AI and Machine Learning keywords is not growing as much in Water Quality studies as in Traffic Flow studies. Furthermore, the use of AI and Machine Learning keywords is not growing as much in Water Quality studies as in Water Research in general suggesting that data-centred approaches may be developing in relation to water issues other than Water Quality.

As shown by the interviews, scholars adopt various strategies regarding the fad for AI and Machine Learning methods. Certain scholars see these methods as not useful for their research purposes, while other consider them as an opportunity for improving classical models and offer better solutions to operational needs. In the vision area, when enough data are available, deep learning methods are now considered more efficient than any other supervised method used in the past, but in most fields, the need for modelling seems far from over. According to one of our interviewees: "There are still some grey areas, situations on which we do not have access to the data and in these cases, we still need to simulate them. There is also the problem of exploiting raw data. In general, it is always useful to pre-process the data and for this purpose, the accumulated knowledge can be useful." (Applied mathematician, 9 January 2018). In addition to the need of enriching the data, it is also important to consider the research purpose. Learning methods might not be suitable for solving all urban problems, and currently, they are mostly used for prediction purposes. Yet, according to the statistician we interviewed, there is a growing interest for optimisation and predictive maintenance issues in Machine Learning and these perspectives might require more interdisciplinary in the future. 
Finally, maybe one of the main pitfalls of machine learning techniques applied to big amounts of data so far is the one cited by one of the economists we met: "With Big Data, the computer will find patterns and laws of evolution but it only works if there really are regularities, so it works if the regularities are maintained." (Economist, 17 February 2018). Working on LUTI models (land-use-transport-interaction), this economist is interested in developing operational tools for planning in the long term. In line with what Batty observed regarding mobility data (2013) and with Te Brömmelstroet et al. (2014), learning methods are not ready to replace classic modelling for such purposes. Hybridising approaches might be an interesting avenue as exemplified by Traffic Flow studies (sections 3.1 and 4.2) and as demonstrated by Hutchins et al. regarding Water Quality studies (2017), but as objected by one of our interviewees, hybridising approaches is challenging and does not always bring exploitable results (Computer scientist, 8 February 2018).

This exploratory study obviously has certain limitations that we should mention.

Firstly, there are limitations related to the choice of bibliometric source and the research protocol. The Web of Science is now in competition and other sources could be used to verify that the results are robust and similar by relying on a different source. Therefore, regarding the question raised by this article, it should be pointed out that the basis of the proceedings is not exhaustive and that other sources, such as Dimensions, for example, could be used to query more conferences proceedings but also pre-publications. Dimensions also allows keyword queries to be made in the full text of the publications. Searching by keywords has significant advantages in terms of corpus delimitation and is more easily reproducible. Using the queries we have defined to categorise publications into AI, Big Data and Machine Learning (see Appendix), it is indeed possible to transpose our approach to other urban issues. To facilitate this, we have made available the query history, data and scripts used to generate the graphs presented in an online git repository ${ }^{4}$. As AI and data science are developing rapidly, the keyword list could be updated to include most recent, methods and techniques (e.g., embedding, transformer, attention). In addition to this work based on lexical queries, the dynamics of cooperation and citations between publications could be analysed to complement and enrich the observations made.

Secondly, there are limitations related to the two urban issues we selected for the study. Indeed, there is no indication that the question of Traffic Flow and that of Water Quality can be generalised and that the dynamics observed around these two issues resemble the dynamics of the other questions relating to transport and water. In our opinion, this limitation also testifies to the interest of the approach we have had. By considering several levels of analysis (that of the urban domain and that of the specific urban issue), we show that the current dynamics are complex and multifaceted and that it is difficult to pronounce on the domain of water in general and on that of transport in general as some authors intend to do (e.g., Bettencourt 2014).

Finally, there is the question of the hindsight we have on the development and adoption of new methods of analysis and new approaches. Studying the contemporary dynamics of science is a challenge that leads to frustration in the sense that it is difficult to reach a clearcut conclusion. This difficulty justifies the adoption of our mixed approach, which articulates the observations gathered in interviews with bibliometric observations. Interestingly, the two approaches have been complementary in the course of this research. Notably, the choice of particular cases and the desire to have a dual approach by field and by urban issue is a direct result of what the interviews have taught us about the dynamics at work among AI and Big Data scientists and among urban modelling scientists.

\section{Conclusion}

In this article, we questioned the academic dynamics associated with the transformations at work in urban management in the era of AI and Big Data. The first part of the article provides an overview of the literature analysing these developments. The need

\footnotetext{
${ }^{4}$ Scripts and data to reproduce the figures of the research article: "The future of urban models in the Big Data and AI era: a bibliometric analysis (2000-2019)." URL: https://zenodo.org/record/4537210
} 
to clarify what is meant by AI, Big Data and Machine Learning is considered. In addition, we note the need to take into account the way these approaches are developing within the academic world linked to the urban environment. Research on the ongoing transformations in the management of urban systems and on the subject of the cities of tomorrow generally does not consider these internal dynamics. Therefore, we argue that there is a need for refocussing on the academia helix, its internal transformation, and the evolution of its relations with the three other helices, namely the political world, the economic world and the social world. In this perspective, we monitored the adoption of AI and Big Data approaches in two urban fields: transportation and water; and two urban issues: traffic flow and water quality. To do so, we relied on the content of interviews and on bibliometric data.

First, we measured the evolution of the number of publications using AI and Big Data keywords in the two fields and urban issues under study. To detect if these urban issues were also attracting interest among specialists of AI and Big Data methods, we measured the number of publications on traffic flow and water quality in computer science, mathematics and physics journal. To finish, we focussed on significant changes in the vocabulary used in traffic flow and water quality publications' abstracts before and after 2012. This method helped us identifying significant differences between the two urban issues. These differences can be explained by the different culture of the research communities concerned with these issues; by the type of data and model associated with them; and by the greater or lesser ability to monitor them on a real-time basis.

Our bibliometric study demonstrates that traffic flow as well as transportation studies are focussing more and more on AI and Big Data and that traffic flow studies are arousing a growing interest among computer scientists, while, so far, this interest is less pronounced in the water research area, and more especially regarding water quality. To go further in the understanding of current research dynamics, we refer to the content of the interviews we performed in Paris and Edinburgh. The interviews helped us to specify the bibliometric research protocol, to select the case of the traffic issue and that of water quality and to understand the possible causes of the differences observed between these two issues.

To deepen the observations obtained on the competition between traditional modelling approaches and new data-centric approaches, other approaches could be interesting. In particular, studying the evolving citation behaviours of authors publishing in urban fields might help identifying ongoing transformations within these fields. In addition, it could be useful to follow the publication behaviour of a specific cohort of scholars specialized in a given urban issue. Doing so could help distinguishing between scholars that consider new techniques by citing external publications on AI and Big Data and scholars that keep referring to traditional references of their field and applying classical modelling methods. In addition, it could be interesting to focus on the locations and institutional affiliations of these authors. Indeed, we could imagine that scholars' strategies varies according to their setting. In the case of the two places, where we conducted interviews, we observed very distinct discourses driven by very distinct institutional strategies.

The results of this article testify to the heterogeneity of the current dynamics, the variety of discourses on what is happening and the differences between urban issues and research communities. Awareness of this heterogeneity appears to be particularly important if we want to be able to cope with future changes in urban management in our cities. Not all researchers in relation to operational issues have the same strategies, data and means to adapt to the changes that are taking place. The interest in and access to new data also varies from one research field to another. While it is conceivable that more data-centred approaches will develop at the operational level in the coming years, the observations in our article suggest that these developments, while they should not fundamentally alter the work of scientists committed to understanding, explaining and predicting the behaviour of urban systems, are nevertheless likely to enrich it and make it evolve.

\section{Acknowledgements}

This work was carried out within the framework of the "City and Digital" working group of the "Urban Futures" Labex within the I-SITE FUTURE (16-IDEX-0003). It was funded through a post-doctoral contract within the joint research unit UMR LATTS in 2018. The 
fieldwork carried out in Edinburgh was supported by an IASH fellowship. I would like to thank the interviewees for their time and the qualitative insights they brought to this exploratory work. I would also like to thank P. Tubaro, A. Casilli and E. Ollion for organising an inspiring research day about "the Big Data moment in Social Sciences" on the 21 February 2019 in Paris.

\section{References}

Adamala S (2017) An overview of Big Data applications in water resources engineering. Machine Learning Research 2:10-18. https://doi.org/10.11648/j.mlr.20170201.12

Agrawal D, Bernstein P, Bertino E, et al (2012) Challenges and opportunities with Big Data: a white paper prepared for the Computing Community Consortium committee of the Computing Research Association

Anderson C (2008) The end of theory: the data deluge makes the scientific method obsolete. In: wired.com. https://www.wired.com/2008/06/pb-theory/. Accessed 16 Aug 2018

Anttiroiko A-V, Valkama P, Bailey SJ (2014) Smart cities in the new service economy: building platforms for smart services. AI \& SOCIETY 29:323-334. https://doi.org/10.1007/s00146-013-0464-0

Bassoo V, Ramnarain-Seetohul V, Hurbungs V, et al (2018) Big Data analytics for smart cities. In: Dey N, Hassanien AE, Bhatt C, et al. (eds) Internet of Things and Big Data analytics toward next-generation intelligence. Springer International Publishing, Cham, pp 359379

Batty M (2013) Big Data, smart cities and city planning. Dialogues in Human Geography 3:274-279. https://doi.org/10.1177/2043820613513390

Batty M (2014) Can it happen again? Planning support, Lee's requiem and the rise of the smart cities movement. Environ Plann B Plann Des 41:388-391. https://doi.org/10.1068/b4103c2

Batty M (2016) Big Data and the city. Built Environment 42:322-337. https://doi.org/10.2148/benv.42.3.321

Bettencourt LMA (2014) The uses of Big Data in cities. Big Data 2:12-22. https://doi.org/10.1089/big.2013.0042

Borkowska K, Osborne M (2018) Locating the fourth helix: rethinking the role of civil society in developing smart learning cities. International Review of Education 64:355-372. https://doi.org/10.1007/s11159-018-9723-0

Boyd D, Crawford K (2012) Critical questions for Big Data. Information, Communication \& Society 15:662-679. https://doi.org/10.1080/1369118X.2012.678878

Cardon D, Cointet J-P, Mazières A (2018) La revanche des neurones. L'invention des machines inductives et la controverse de l'intelligence artificielle. Réseaux 211:173-220. https://doi.org/10.3917/res.211.0173

Carmichael I, Marron JS (2018) Data science vs. statistics: two cultures? Jpn J Stat Data Sci $1: 117-138$

Chen PCL, Zhang C-Y (2014) Data-intensive applications, challenges, techniques and technologies: a survey on Big Data. Information Sciences 275:314-347. https://doi.org/10.1016/j.ins.2014.01.015

Chui M, Manyika J, Miremadi M et al. (2018) Notes from the AI Frontier: insights from hundreds of use cases. McKinsey Global Institute

Courmont A (2018) Platform, big data and the reshaping of urban government: the effects of Waze on traffic regulation policies. Revue Française de Sociologie 59:423-449

Crandall J (2010) The geospatialization of calculative operations: tracking, sensing and megacities. Theory, Culture \& Society 27:68-90. https://doi.org/10.1177/0263276410382027

Engin Z, van Dijk J, Lan T, et al (2020) Data-driven urban management: mapping the landscape. Journal of Urban Management 9:140-150. https://doi.org/10.1016/j.jum.2019.12.001

Etzkowitz H, Leydesdorff L (2000) The dynamics of innovation: from National Systems and "Mode 2" to a Triple Helix of university-industry-government relations. Research policy 29:109-123 
Gao J, Zhang Y-C, Zhou T (2019) Computational socioeconomics. ArXiv arXiv:1905.06166. https://arxiv.org/pdf/1905.06166.pdf

Gingras Y (2018) Evolution of science policy in Quebec and Canada. CIRST, UQAM, Montréal

González-Bailón S (2013) Social science in the era of big data. Policy \& Internet 5:147-160. https://doi.org/10.1002/1944-2866.POI328

Goodchild MF (2007) Citizens as sensors: the world of volunteered geography. GeoJournal 69:211-221. https://doi.org/10.1007/s10708-007-9111-y

Goodfellow IJ, Pouget-Abadie J, Mirza M et al. (2014) Generative adversarial networks. ArXiv arXiv:1406.2661v1, https://arxiv.org/pdf/1406.2661v1.pdf

Graham M, Shelton T (2013) Geography and the future of big data, big data and the future of geography. Dialogues in Human Geography 3:255-261. https://doi.org/10.1177/2043820613513121

Gray S, O'Brien O, Hügel S (2016) Collecting and visualizing real-time urban data through city dashboards. Built Environment 42:498-509. https://doi.org/10.2148/benv.42.3.498

Grossetti M, Boë L-J (2008) Sciences humaines et recherche instrumentale : qui instrumente qui ? L'exemple du passage de la phonétique à la communication parlée. Revue d'Anthropologie des Connaissances 2, 1:97-114. https://doi.org/10.3917/rac.003.0097

Huang Y, Schuehle J, Porter AL, Youtie J (2015) A systematic method to create search strategies for emerging technologies based on the Web of Science: illustrated for 'Big Data.' Scientometrics 105:2005-2022. https://doi.org/10.1007/s11192-015-1638-y

Hutchins MG, McGrane SJ, Miller JD, et al (2017) Integrated modeling in urban hydrology: reviewing the role of monitoring technology in overcoming the issue of 'big data' requirements. WIREs Water 4:e1177. https://doi.org/10.1002/wat2.1177

Jesse N (2018) Internet of Things and Big Data: the disruption of the value chain and the rise of new software ecosystems. AI \& SOCIETY 33:229-239. https://doi.org/10.1007/s00146-018-0807-y

Kalantari A, Kamsin A, Kamaruddin HS, et al (2017) A bibliometric approach to tracking big data research trends. Journal of Big Data 4:30. https://doi.org/10.1186/s40537-017-0088$\underline{1}$

Kandt J, Batty M (2021) Smart cities, Big Data and urban policy: towards urban analytics for the long run. Cities 109:102992. https://doi.org/10.1016/j.cities.2020.102992

Kitchin R (2016) The ethics of smart cities and urban science. Philosophical Transactions of the Royal Society A: Mathematical, Physical and Engineering Sciences 374:20160115. https://doi.org/10.1098/rsta.2016.0115

Kitchin R, Lauriault TP, McArdle G (2017) Data and the city. Taylor \& Francis

Komninos N (2016) Intelligent cities and the evolution toward technology-enhanced, global and user-driven territorial systems of innovation. In: Handbook on the geographies of innovation. Edward Elgar Publishing Limited, Cheltenham, UK; Northhampton, MA, USA, pp 187-200

Korukonda AR (2007) Technique without theory or theory from technique? An examination of practical, philosophical, and foundational issues in data mining. AI \& SOCIETY 21:347355. https://doi.org/10.1007/s00146-006-0064-3

Laborie B, Rocher V, Vilmin L, et al (2016) Le modèle de prédiction de la qualité de la Seine ProSe. TSM 43-66. https://doi.org/10.1051/tsm/201611043

Lobo J, Alberti M, Allen-Dumas M, et al (2020) Urban Science: integrated theory from the first cities to sustainable metropolises (January 28, 2020). Report submitted to the NSF on the Present State and Future of Urban Science. http://dx.doi.org/10.2139/ssrn.3526940

Lungarella M, Iida F, Bongard JC, Pfeifer R (2007) AI in the 21st Century - with historical reflections. In: Lungarella M, lida F, Bongard J, Pfeifer R (eds) 50 Years of Artificial Intelligence: essays dedicated to the 50th Anniversary of Artificial Intelligence. Springer Berlin Heidelberg, Berlin, Heidelberg, pp 1-8

Pan Y, Tian Y, Liu X, et al (2016) Urban Big Data and the development of cityi. Engineering 2:171-178. https://doi.org/10.1016/J.ENG.2016.02.003

Park S-C (2018) The Fourth Industrial Revolution and implications for innovative cluster policies. AI \& SOCIETY 33:433-445. https://doi.org/10.1007/s00146-017-0777-5 
Polonetsky J, Tene O (2013) Privacy and Big Data: making ends meet. Stanford Law Review 66:

Ratinaud P (2008) IRaMuTeQ (computer software)

Rincon-Patino J, Ramirez-Gonzales G, Corrales JC (2018) Exploring machine learning: a bibliometric general approach using Citespace [version 1; referees: 1 approved, 1 approved with reservations]. F1000Research 7:1240. https://doi.org/10.12688/f1000research.15619.1

Sainct R (2016) Étude des instabilités dans les modèles de trafic. Thesis in Mathematics, ParisEst University

Sha XW, Carotti-Sha G (2016) Big Data. AI \& SOCIETY. https://doi.org/10.1007/s00146$\underline{016-0662-7}$

Sivarajah U, Kamal MM, Irani Z, Weerakkody V (2017) Critical analysis of Big Data challenges and analytical methods. Journal of Business Research 70:263-286. https://doi.org/10.1016/j.jbusres.2016.08.001

Stilgoe J (2017) Machine learning, social learning and the governance of self-driving cars. Soc Stud Sci 48:25-56. https://doi.org/10.1177/0306312717741687

Te Brömmelstroet M, Pelzer P, Geertman S (2014) Forty years after Lee's requiem: are we beyond the seven sins? Environ Plann B Plann Des 41:381-387. https://doi.org/10.1068/b4103c

Thatcher J (2014) Big Data, big auestions| living on fumes: digital footprints, data fumes, and the limitations of spatial Big Data. International Journal of Communication 8:

Turchin A, Denkenberger D (2018) Classification of global catastrophic risks connected with artificial intelligence. AI \& SOCIETY. https://doi.org/10.1007/s00146-018-0845-5

Zheng Y, Capra L, Wolfson O, Yang H (2014) Urban Computing: concepts, methodologies, and applications. ACM Trans Intell Syst Technol 5:2157-6904. https://doi.org/10.1145/2629592 


\section{Appendix}

Lexical queries used to retrieve Big Data, AI and Machine Learning publications

\begin{tabular}{|c|c|}
\hline Logic Based Al & $\begin{array}{l}\text { TS = ("knowledge representation*" OR "expert system*" OR } \\
\text { "knowledge based system*" OR "inference engine*" OR "search } \\
\text { tree*" OR "minimax" OR "tree search" OR "Logic programming" OR } \\
\text { "theorem prover*" OR ("planning" AND "logic") OR "logic } \\
\text { programming" OR "lisp" OR "prolog" OR "deductive database*" OR } \\
\text { "nonmonotonic reasoning*") }\end{array}$ \\
\hline Connectionist $\mathrm{Al}$ & $\begin{array}{l}\text { TS = ("artificial neural network*" OR "Deep learning" OR } \\
\text { "perceptron*" OR "Backprop*" OR "Deep neural network*" OR } \\
\text { "Convolutional neural network*" OR ("CNN" AND "neural network*") } \\
\text { OR ("LSTM" AND "neural network*") OR ("recurrent neural } \\
\text { network*" OR ("RNN*" AND "neural network*")) OR "Boltzmann } \\
\text { machine*" OR "hopfield network*" OR "Autoencoder*" OR "Deep } \\
\text { belief network*" OR "adversarial neural network*" OR "generative } \\
\text { adversarial network*" OR ("ANN\$" AND "neural network*") OR } \\
\text { ("GAN\$" AND "neural network*")) }\end{array}$ \\
\hline Big Data & $\begin{array}{l}\text { TS = ("Big Data*" OR Bigdata* OR "MapReduce*" OR } \\
\text { "Map\$Reduce*" OR Hadoop* OR Hbase OR "No SQL" OR } \\
\text { "NoSQL" OR "NoSQL Database" OR Newsql OR Big Near/1 Data } \\
\text { OR Huge Near/1 Data OR "Massive Data" OR "Data Lake" OR } \\
\text { "Massive Information" OR "Huge Information" OR "Big } \\
\text { Information" OR "Large-scale Data*" OR "Largescale Data*" OR } \\
\text { Petabyte OR Exabyte OR Zettabyte OR "Semi-Structured Data" } \\
\text { OR "Semistructured Data" OR "Unstructured Data") }\end{array}$ \\
\hline $\begin{array}{l}\text { Machine Learning, } \\
\text { else }\end{array}$ & $\begin{array}{l}\text { TS = ("Machine* Learn*" OR "Support Vector Machine\$" OR "Support } \\
\text { Vector Network\$" OR "Random Forest\$" OR "Genetic Algorithm\$" OR } \\
\text { "Bayes* Network\$" OR "belief network\$" OR "directed acyclic } \\
\text { graphic*" OR "supervised learn*" OR "semi\$supervised learn*" OR } \\
\text { "unsupervised learn*" OR "reinforcement learn*" OR "turing learn*") } \\
\text { NOT TS = ("knowledge representation*" OR "expert system*" OR } \\
\text { "knowledge based system*" OR "inference engine*" OR "search } \\
\text { tree*" OR "minimax" OR "tree search" OR "Logic programming" OR } \\
\text { "theorem prover*" OR ("planning" AND "logic") OR "logic } \\
\text { programming" OR "lisp" OR "prolog" OR "deductive database*" OR } \\
\text { "nonmonotonic reasoning*" OR "artificial neural network*" OR "Deep } \\
\text { learning" OR "perceptron*" OR "Backprop*" OR "Deep neural } \\
\text { network*" OR "Convolutional neural network*" OR ("CNN" AND } \\
\text { "neural network*") OR ("LSTM" AND "neural network*") OR } \\
\text { ("recurrent neural network*" OR ("RNN*" AND "neural network*")) } \\
\text { OR "Boltzmann machine*" OR "hopfield network*" OR } \\
\text { "Autoencoder*" OR "Deep belief network*" OR "adversarial neural } \\
\text { network*" OR "generative adversarial network*" OR ("ANN\$" AND } \\
\text { "neural network*") OR ("GAN\$" AND "neural network*") OR ("Big } \\
\text { Data*" OR Bigdata* OR "MapReduce*" OR "Map\$Reduce*" OR } \\
\text { Hadoop* OR Hbase OR "No SQL" OR "NoSQL" OR "NoSQL Database" } \\
\text { OR Newsql OR Big Near/1 Data or Huge Near/1 Data OR "Massive } \\
\text { Data" OR "Data Lake" OR "Massive Information" OR "Huge } \\
\text { Information" OR "Big Information" OR "Large-scale Data*" OR } \\
\text { "Largescale Data*" OR Petabyte OR Exabyte OR Zettabyte OR "Semi- } \\
\text { Structured Data" OR "Semistructured Data" OR "Unstructured Data")) }\end{array}$ \\
\hline
\end{tabular}

